\title{
Numerical Simulations of Strong-Plume Driven Ceiling Flows
}

\author{
PRATEEP CHATTERJEE, KARL V. MEREDITH, BENJAMIN DITCH, HONG-ZENG YU, \\ YI WANG and FRANCESCO TAMANINI \\ FM Global, Research Division \\ 1151 Boston-Providence Turnpike, Norwood, MA 02062, USA
}

\begin{abstract}
Large eddy simulations (LES) of ceiling flow driven by strong-plumes of rack-storage fires have been simulated for a range of convective heat release rates (HRR) and ceiling heights. An actual delivered density (ADD) apparatus plume generator burner setup has been modeled using buoyant diffusion flames and with the inclusion of an upstream airflow vent producing the higher plume velocities observed in rack-storage fires. Computed results for plume centerline excess temperature and velocity have been compared against experimental data. In addition to the modeled burner setup, an alternate volumetric HRR source has also been applied in the simulations. Flows under ceilings located at different heights above the ADD apparatus have been simulated. Various convective HRR plumes have been used and the resulting ceiling flow radial distributions of computed excess temperature and velocity have been compared against experimental measurements. Predicted temperature and radial velocity profiles have also been shown to agree favorably with experimental data at two depths below the ceiling heights. Comparison of ceiling layer depths have also shown good comparison with an empirical correlation.
\end{abstract}

\section{KEYWORDS: $C F D$, rack-storage fire plume, ADD apparatus, ceiling flow, sprinkler activation, RTI}

\section{INTRODUCTION}

Ceiling flows caused by fires are responsible for the distribution of combustion products (e.g. smoke) in storage occupancies, heat transfer to the ceiling, but more importantly, these flows are responsible for the activation of automatic sprinklers that are generally located below the ceiling. With the advancement of computational fluid dynamics (CFD) modeling in fire-growth predictions with the application of combustion [1,2], radiation [2,3] and pyrolysis modeling [2,4] and water-based suppression calculations [5], full-scale simulations of industrial scale fire scenarios are made possible [6,7]. An important component of the model is its ability to accurately estimate the activation of sprinklers which are the source of water-sprays for suppression modeling. Response time index (RTI) calculations [8] are used to predict the activation time. RTI calculations are traditionally performed with application of the maximum ceiling layer excess temperature and velocity obtained from correlations [9]. As full-scale CFD simulations aim to model activation of automatic sprinklers whose links are located at various heights below the ceiling depending on the sprinkler type, the use of maximum ceiling layer temperature and velocity is not sufficient to provide accurate activation times. Predictions of spatial distributions of temperature and velocity below the ceiling are therefore required.

Ceiling-jets evolve from the impingement of fire-generated plume on a ceiling and the resulting turning of the flow towards the radial direction. Ceiling layer flows were originally studied by Alpert [10] who proposed correlations based on an experimental study and theoretical analysis based on the Boussinesq assumption. You and Faeth [11] extended the work to strong-plume driven ceiling flows, where the density difference between the ceiling flow and the ambient air cannot be neglected. Motevalli [12] applied a hybrid empiricalnumerical model to simulate weak plume driven ceiling flows. Cox and Kumar [13] have applied RANSbased modeling with the law of the wall model to study flows adjacent to the ceiling in enclosure flows. Tuovinen [14] applied the same RANS code to study ceiling flows caused by $t^{2}$-fires. Detailed predictions of ceiling layer temperatures have been previously reported in Fire Dynamics Simulator (FDS) studies [2], however accuracy of velocity profile computations in the ceiling layers were not reported. Several numerical studies of ceiling flows in tunnel like enclosures are reported in literature [2].

Recent numerical studies of unconfined ceiling flows have applied both RANS and LES methods. Chow [15] applied RANS modeling to study transient behavior of fire plumes and ceiling jets with particular emphasis on investigation of air entrainment rates. Hara et al [16] used $k-\varepsilon$ modeling to investigate ceiling flows of plumes generated by $0.15-0.61 \mathrm{~m}$ diameter propane fires of chemical HRR, $\dot{Q}_{c h}=11.6-191 \mathrm{~kW}$ and ceiling heights, FIRE SAFETY SCIENCE-PROCEEDINGS OF THE ELEVENTH INTERNATIONAL SYMPOSIUM pp. $458-471$ 
$H$, in the range of 1.5 and $2.5 \mathrm{~m}$. The effect of mesh-size on the results was extensively studied, however only non-dimensionalized maximum excess temperature were compared against experimental data of Heskestad and Hamada [17]. O'Grady and Novozhilov [18] used FDS to model ceiling flows in a compartment fire scenario. Their modeled fire had a $\dot{Q}_{c h}$ of $1500 \mathrm{~kW}$ and the ceiling height was $H=6.0 \mathrm{~m}$. Computed ceiling layer excess temperature and velocity profiles were compared with experimental data and mesh-sensitivity was studied. The smallest mesh size used in the study was $7.5 \mathrm{~cm}$ and results were shown to converge asymptotically, although smaller mesh size results were not reported. For good estimation of ceiling layer flows, accurate modeling of fire plumes is of importance. In order to simulate rack-storage fire plumes, Bill [19] and Nam [20] have modeled the ADD plume generator with the application of volumetric sources of HRR. The volumetric source size and spatial location were adjusted by trial and error so that the simulated plume temperature and velocity distributions matched the experimental results.

The objective of the present study is to simulate ceiling flows resulting from strong plumes typical of industrial-scale storage fires. Ceiling heights, $H=3.0,4.5$, and $6.0 \mathrm{~m}$ and convective HRR of $\dot{Q}_{c}=1500$, 3000 and $5000 \mathrm{~kW}$ were selected for the simulations. Numerical studies with such range of ceiling heights and larger convective HRR values are not reported in literature, to the best of the authors' knowledge. A newer version of the ADD apparatus [19] fire plume generator has been modeled for computation of the fire plumes of interest. The ADD apparatus burners provide representative plumes of rack-storage fires with the advantage of providing a steady flow, which is not possible in growing rack-storage fires. The resulting steady ceiling flows provide good estimates of time-averaged temperature and velocity profiles. This is advantageous for validation of the LES results. The aim is to provide accurate estimation of ceiling layer temperature and velocity profiles which will be used for automatic sprinkler activation calculations in full-scale simulations of fire growth and suppression phenomena in rack-storage scenarios. The compressible LES code FireFOAM [1] has been used to simulate the plumes and the ceiling flows.

\section{EXPERIMENTAL SETUP}

Two experiments have provided data for comparison with the simulation results. In the first experiment, centerline measurements of temperature and velocity were made to characterize the fire plumes and in the second experiment, ceiling layer temperatures and velocities were measured for the strong-plume driven ceiling-jets. The two experimental setups are described below.

\section{Fire Plume Generator}

The ADD apparatus consists of a series of burners (fire plume generator) and water collection bins that collect sprinkler sprays to provide water distribution measurements. The fire plume generator setup consists of heptane spray fires anchored on several burners comprising of conical spray-discharge nozzles. Figure 1(a) shows a single spray nozzle at the center surrounded by a ring burner arrangement for anchoring propane pilot flames. Nine burners - one central burner and eight on a ring — comprise the burner setup, see Fig. 1(b). The central burner is aligned $90^{\circ}$ to the horizontal whereas the ring burners are oriented $55^{\circ}-80^{\circ}$ to the horizontal. The orientation of the ring burners with respect to the horizontal is varied to elongate or shorten the flames to represent typical fire plumes of rack storage fires. For the centerline temperature and velocity measurement tests, the burners were located $0.225 \mathrm{~m}$ above a $2.25 \mathrm{~m} \times 4.65 \mathrm{~m}$ wide platform that represented the top of the ADD water collection bins. Since the fire plume generator produces representative plumes at the top of rack-storage arrays, increased air flow rates are made possible with the help of an air jet emerging from an opening located on the platform surface below the central burner. The air jet is produced with the help of a centrifugal blower. Flow discharge rates between $0.28-0.33 \mathrm{~m}^{3} / \mathrm{s}$ from the air flow opening augment the velocity field produced by the spray flames. A free-burn fire test of $\dot{Q}_{c}=3500 \mathrm{~kW}$ using the burner setup is shown in Fig. 1(c).

\section{Plume Measurements}

Several free-burn tests were conducted with the fire plume generator under the 20MW fire products collector (FPC) in the FM Global Large Burn Laboratory. Plume centerline excess temperature and velocity were measured in the 1500-7500 kW convective heat range. Data was collected at three elevations-2.57, 4.70, 


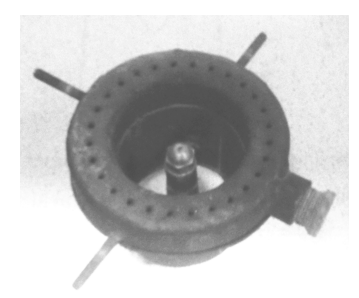

(a)

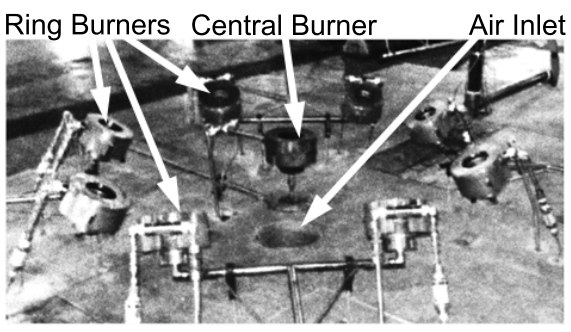

(b)

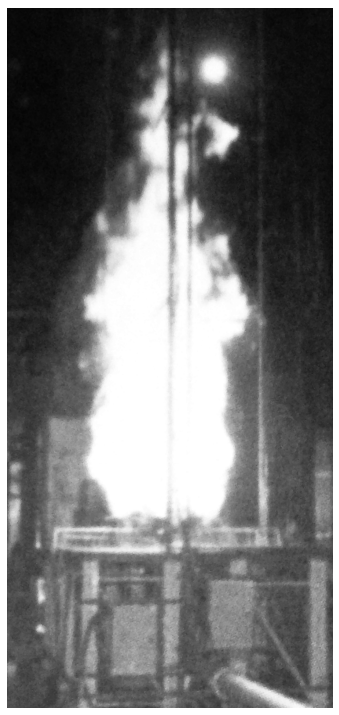

(c)

Fig. 1. ADD fire plume generator: (a) a single burner with the nozzle in the middle and perforated ring burner for premixed propane pilot flames, (b) setup showing the central burner, eight burners on a ring and an air inlet below the central burner, and (c) free-burn at $\dot{Q}_{c}=3500 \mathrm{~kW}$.

and $6.83 \mathrm{~m}$ above the $1.52 \mathrm{~m}$ high test platform. Temperature measurements were recorded with $0.51 \mathrm{~mm}(24-$ gage), inconel-sheathed K-type thermocouples. Velocities were measured with $13 \times 25 \mathrm{~mm}$ long bi-directional probes. The differential pressure from each probe was measured with a Setra Model 264 pressure transducer $( \pm 62 \mathrm{~Pa})$. Accuracy of these transducers is rated at $1 \%$ of full scale. Velocity measurement uncertainties were determined, based on the Bernoulli equation [21], to be about 1.5 and $2.5 \mathrm{~m} / \mathrm{s}$ at gas temperatures of 633 and $1673 \mathrm{~K}$, respectively. Since the radial distributions of plume gas temperature and velocity are close to Gaussian, it was assumed that rack-storage fire plumes are reproduced as long as the centerline values are replicated [22].

\section{Ceiling Flow Measurements}

Following the calibration tests, the fire plume generator was installed over the large-scale ADD water collection pans setup. This apparatus was then used for fire plume development under a ceiling and resulting ceiling layer flows were studied. Excess temperatures and velocities were recorded for a combination of convective HRRs and ceiling heights. Specifically, HRRs of 1500-5000kW were applied and ceiling clearances, $H$, were varied between 3.0 and $6.0 \mathrm{~m}$. Temperatures were recorded with K-type thermocouples for for $d_{p}=0.175 \mathrm{~m}$ depth below the ceiling at $r=2.1$ and $3.9 \mathrm{~m}$ radial distances from the centerline, and for $d_{p}=0.3 \mathrm{~m}$ at $r=0.0,3.0$ and $6.0 \mathrm{~m}$ locations. Bi-directional probes, $19 \times 38 \mathrm{~mm}$ long, with differential pressure transducers $( \pm 125 \mathrm{~Pa})$ were used for velocity measurements at the same radial locations. The velocity measurement uncertainties were estimated to be about 2.1 and $3.5 \mathrm{~m} / \mathrm{s}$ at gas temperatures of 633 and $1673 \mathrm{~K}$, respectively. Tests for each setup involving selected $\dot{Q}_{c}$ and $H$ combinations were repeated three times. The repeat tests yielded excellent agreement for measured temperatures, with velocity measurements also showing scatter of less than $\pm 0.6 \mathrm{~m} / \mathrm{s}$ from the mean values. Time-averaged data were extracted for comparison with computational results with the initial transients excluded from the averaging process.

In addition, non-dimensional ceiling layer maximum excess temperature and velocity data from Heskestad and Hamada [17] and Class 2 and Standard Plastic rack-storage fire test data [23] are used for comparison against simulation results. 


\section{NUMERICAL MODEL}

FireFOAM, a CFD model based on the open source framework OpenFOAM [24], has been used in this study. LES models for buoyant turbulent diffusion combustion [1], thermal radiation heat transfer from soot emission [3], and solid-phase pyrolysis [4] are included in FireFOAM to simulate fire growth. In order to simulate fire suppression, the multiphase flow aspects of fire suppression are also included. A Lagrangian transport model is employed to simulate water droplets originating from a fire sprinkler, transported through a fire plume, and impingement on the burnt and/or unburnt surfaces. A thin film model is included and has been validated for simulating the flow and interaction of liquid water over the solid fuel surfaces [5]. An RTI model has been included in FireFOAM and has been verified to give accurate estimates of sprinkler activation, provided good estimates of ceiling gas temperature and velocity are available. In the present study the combustion, the turbulent flow and radiation models have been used to simulate the fire plumes and resulting ceiling layer flows.

\section{Computational Burner Setup}

Previous attempts at modeling the smaller ADD apparatus with CFD simulations [19] demonstrated good agreement between radial distributions of predicted and experimental temperatures, although details of the experimental burner setup were not included and the convective HRRs were modeled with a volumetric source. Designing the ADD setup with burners poses challenges and previous studies $[19,20]$ have avoided direct simulation of the ADD burners. Radiation from the burner fires may also affect the ceiling flows, although in the present study radiative heating of the ceiling or the sprinkler links are not considered. Simulation with burners will also facilitate investigation of droplet-flame interactions in the future.

The principal aim of designing ADD plume generator fires was to reproduce convective flow fields of rackstorage plumes for application in ceiling flow simulations. Although, spray fires can be directly modeled in OpenFOAM [25], in the present study the effort concentrates on modeling fire plumes on top of rack-storage setups. Therefore, for simplicity, a surrogate fire condition involving propane diffusion flames anchored over a set of burners has been modeled, see Fig. 2(a). The central and ring burner concepts are retained from the experimental setup and an upstream nozzle was used to augment the convective field generated by the buoyant diffusion flames. The overall width of the burner setup matched the experimental setup dimensions. The convective flow fields generated have been compared against centerline velocity and temperature data along with comparisons against correlations. Radial distributions of velocity and temperature have also been investigated to evaluate plume growth.

As can be observed in Fig. 2(b), the burner setup was located above a $0.3 \mathrm{~m}$ tall platform (representing the ADD water collection setup) with the bottom of the central burner (located $0.127 \mathrm{~m}$ above the platform) providing an obstruction to the incoming flow from the air inlet on the platform. The airflow goes around the central burner to provide higher vertical velocities between the ring and central burners. A $24 \mathrm{~m} \times 24 \mathrm{~m}$ ceiling, located 3.0-6.0 $\mathrm{m}$ above the platform was included in the setup, see Fig. 2(b).

\section{Volumetric Plume Source}

As in previous studies [19,20], a volumetric plume source has also been applied to compare its performance against the designed burner results for $\dot{Q}_{c}=1500 \mathrm{~kW}$. However, unlike the use of a cylindrical volumetric source as in Ref. [19], the present study uses a smaller volume located below the virtual origin of the modeled fires, i.e. the top of the volumetric source aligns with the virtual origin height. Ideally, a point source of HRR located at the virtual origin would be the perfect representation of a virtual source. However, inclusion of such an infinitesimally small source is difficult in LES models. Therefore, a finite volume of $\sim 0.3 \mathrm{~m}^{3}$ was used to release the entire chemical HRR, $\dot{Q}_{c h}$, of the fire with a specified overall radiant fraction, $\chi_{r}$, to provide the required convective HRR, $\dot{Q}_{c}$, as the plume source. The target $\dot{Q}_{c h}$ value along with the source volume, $V\left(\mathrm{~m}^{3}\right)$ and a fuel heat of combustion, $\Delta H_{c}(\mathrm{~J} / \mathrm{kg})$ produces a pseudo-fuel consumption rate of $\dot{Q}_{c h} /\left(V \Delta H_{c}\right)\left(\mathrm{kg} / \mathrm{m}^{3}\right.$ $\mathrm{s}$ ), which was used to generate the products of combustion, $\mathrm{CO}_{2}$ and $\mathrm{H}_{2} \mathrm{O}$, by applying the consumption rate in the species transport equations. 


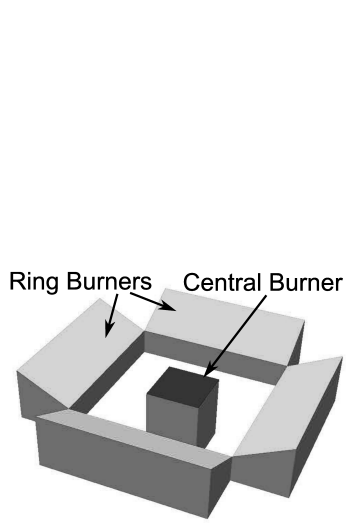

(a)
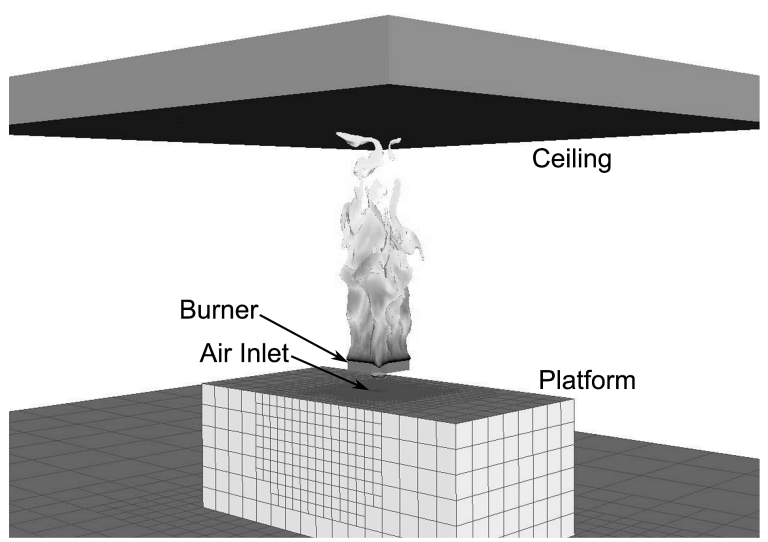

(b)

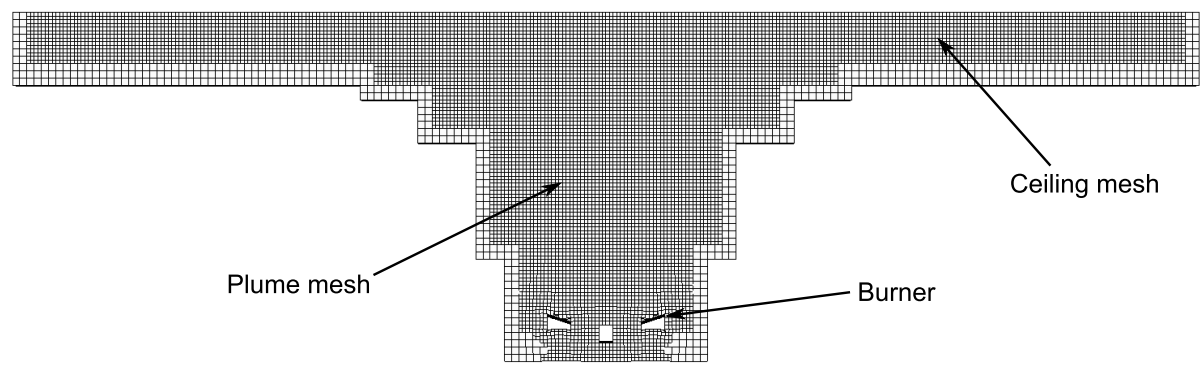

(c)

Fig. 2. Computational setup showing (a) the burner setup, (b) the ceiling, a $\dot{Q}_{c h} \approx 2100 \mathrm{~kW}\left(\dot{Q}_{c}=1500 \mathrm{~kW}\right)$ simulated ADD burner fire, the platform representing the top of the ADD water collection pans, the air inlet location on the platform and the burner, and (c) the $(3.0 \mathrm{~cm})^{3}$ mesh in the plume and ceiling regions.

\section{Computational Mesh}

The mesh was generated with an open-source CAD program, Salome [26], and using the OpenFOAM [24] mesh generation utility snappyHexMesh. Hexahedral cells with local refinement were generated with a fine mesh resolution of $(3.0 \mathrm{~cm})^{3}$. The fine mesh in the computational domain is shown in Fig. 2(c)-the mesh was refined such that the plume radial growth was modeled accurately and the flow below the ceiling was also adequately resolved spatially. Mesh resolution studies were conducted with the aim of demonstrating reasonable mesh independence comparing the centerline plume temperature and velocity against experimental data. A finest mesh size of $(1.5 \mathrm{~cm})^{3}$ was necessary for the higher convective HRRs $(>5000 \mathrm{~kW})$, whereas the $(3.0 \mathrm{~cm})^{3}$ grid showed mesh-independence for the 1500 and $4500 \mathrm{~kW}$ convective HRRs. The ceiling layer finest mesh was located in a $10 \mathrm{~m} \times 10 \mathrm{~m}$ region around the ceiling centerline, down to $0.48 \mathrm{~m}$ below the ceiling. For certain cases the finest mesh region below the ceiling was extended to a $13 \mathrm{~m} \times 13 \mathrm{~m}$ region. This setup, however, required a much higher computational expense and in general was not used for the majority of the simulations.

\section{Solution Settings}

Propane fires of $\dot{Q}_{c h} \approx 2100,6600$ and $11500 \mathrm{~kW}$ were simulated (see Fig. 3) with constant applied $\chi_{r}=0.3$, 0.32 and 0.35 to generate plumes of $\dot{Q}_{c}=1500,4500$ and $7500 \mathrm{~kW}$, respectively. The $\chi_{r}$ values were obtained from experimental measurements of $\dot{Q}_{c h}$ and $\dot{Q}_{c}$ recorded in the $20 \mathrm{MW} \mathrm{FPC}$. The $\dot{Q}_{c}=1500 \mathrm{~kW}$ plume was applied towards simulating flows under ceilings located at $H=3.0,4.5$ and $6.0 \mathrm{~m}$ above the ADD apparatus water collection setup. In addition, based on the plume simulation conditions mentioned above $\left(\dot{Q}_{c}=1500\right.$ $7500 \mathrm{~kW}$ ), two other plume conditions were designed, $\dot{Q}_{c}=3000$ and $5000 \mathrm{~kW}$ and were applied towards flows under taller ceilings: $H=4.5$ and $6.0 \mathrm{~m}$. 
At the ceiling, the law of the wall boundary condition [27] was applied for subgrid-scale viscosity in addition to the no-slip boundary condition for velocity. An isothermal condition was applied for the ceiling temperature $\left(T_{\text {wall }}=298.15 \mathrm{~K}\right)$. It was determined, with simulations, that the ceiling temperature boundary conditioneither adiabatic or isothermal — has marginal effect on the velocity and thermal boundary layer characteristics in the simulation time period employed in the present study, except in the immediate vicinity of the ceiling; this has also been shown in experimental studies [10]. In reality, the exact thermal boundary condition at the ceiling would be somewhere between the isothermal and adiabatic conditions.

\section{RESULTS AND DISCUSSION}

Results are first presented for the plume simulations followed by the ceiling flow simulations. From the plume simulations, $60 \mathrm{~s}$ averaged numerical results are compared with experimental data. Plume radial distributions of velocity and temperature compared favorably against Gaussian distributions but are not reported here. Results presented from the ceiling flow simulations are for the ADD burner cases, except in Fig. 10 where the volumetric fire source results are also shown. Time-averaged maximum excess temperature and velocity profiles extracted from simulation results are next compared against experimental data for ceiling flows. The maximum ceiling-jet temperature and velocity were calculated for several radial locations. Time-averaged velocity and excess temperature profiles as functions of radial distance were extracted from the simulation results for two depths -0.175 and $0.3 \mathrm{~m}$ below the ceiling and are described. Finally, predicted ceiling flow thermal and velocity layer thicknesses are compared against correlation results.

\section{Fire Plume Characterization}

The primary purpose of designing the simulated fires was to reproduce temperatures and velocities representative of rack-storage fire plume distributions. Figure 3 shows instantaneous snapshots of the three modeled fires corresponding to $\dot{Q}_{c}=1500,4500$ and $7500 \mathrm{~kW}$. Flame heights of $2.91,5.15$ and $6.70 \mathrm{~m}$ were predicted for $\dot{Q}_{c}=1500,4500$ and $7500 \mathrm{~kW}$, respectively. These compared favorably with flame heights estimated from experiments. The air inlet located below the central burner provided additional airflows to the burner generated plumes so that rack-storage fire plume velocities could be achieved. In the experimental setup, the inlet air velocities varied between 8 and $9.3 \mathrm{~m} / \mathrm{s}$, corresponding to 1500 and $7500 \mathrm{~kW}$ plumes, respectively. However, for the simulations, velocities at the inlet were varied between 10 and $20 \mathrm{~m} / \mathrm{s}$. This is because the experimental burner setup involves spray flames that produce jet flames of high momentum. Higher velocities are required in the simulations applying buoyant diffusion flames of propane, which do not provide sufficient momentum to the resulting plumes as compared to the spray flames. Similar to previous studies [19], by adjusting the air inlet velocities a reasonably accurate match with experimental results was obtained.

As a reference case, results from the simulation of the $\dot{Q}_{c}=1500 \mathrm{~kW}$ plume with the volumetric fire source are shown in Fig. 4. The volumetric plume source, not surprisingly, produces good comparisons-the computed temperature distribution matches the experimental data and its slope compares well with the correlation between 2.5 and $6 \mathrm{~m}$; velocities are slightly over-predicted compared to the correlation values, however they fall within the experimental uncertainty. Figure 4 also shows the predicted centerline excess temperature and velocity using the burner setup, compared against experimental data and correlations [28] for $\dot{Q}_{c}=1500 \mathrm{~kW}$. Here, it should be mentioned that plume centerline temperatures from the thermocouples were corrected for radiation loss by equating convective heat transfer (calculated with the application of a Nusselt number correlation) from the hot gases to the thermocouple bead to the radiation loss from the bead to the ambient. An optimum condition with inlet air velocity of $10 \mathrm{~m} / \mathrm{s}$ was determined with emphasis given to the temperature profile as RTI is strongly affected by temperature variation as compared to velocity on which there is a square-root dependence.

Inlet air velocities for higher $\dot{Q}_{c}$ were increased considerably and values of 15 and $20 \mathrm{~m} / \mathrm{s}$ were applied for $\dot{Q}_{c}=4500$ and $7500 \mathrm{~kW}$, respectively. Although the inlet air velocity doubles from $10 \mathrm{~m} / \mathrm{s}$ for $\dot{Q}_{c}=1500 \mathrm{~kW}$ to $20 \mathrm{~m} / \mathrm{s}$ for $\dot{Q}_{c}=7500 \mathrm{~kW}$, the effective upstream air velocities contributing to the plume development are lower as the air inlet flow is obstructed at the bottom of the central burner, see Fig. 2(a). Comparisons of predicted excess temperature and velocity with experimental data and correlation are shown in Fig. 5. The 


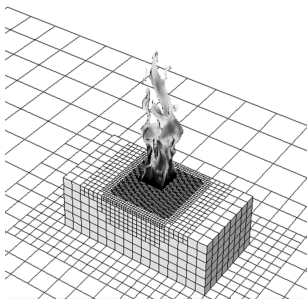

(a)

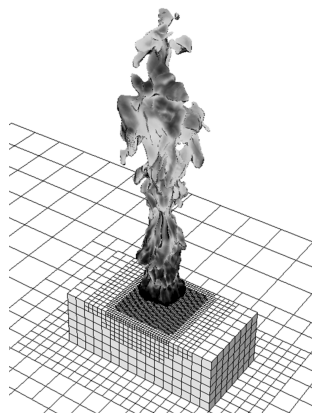

(b)

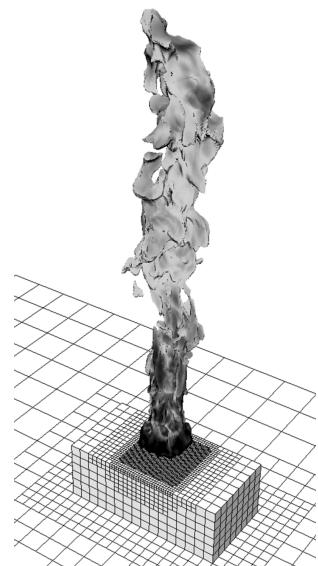

(c)

Fig. 3. Modeled fires anchored on the burner setup corresponding to $\dot{Q}_{c}=$ (a) 1500, (b) 4500, and (c) $7500 \mathrm{~kW}$, illustrated with the instantaneous isocountour of stoichiometric mixture fraction.

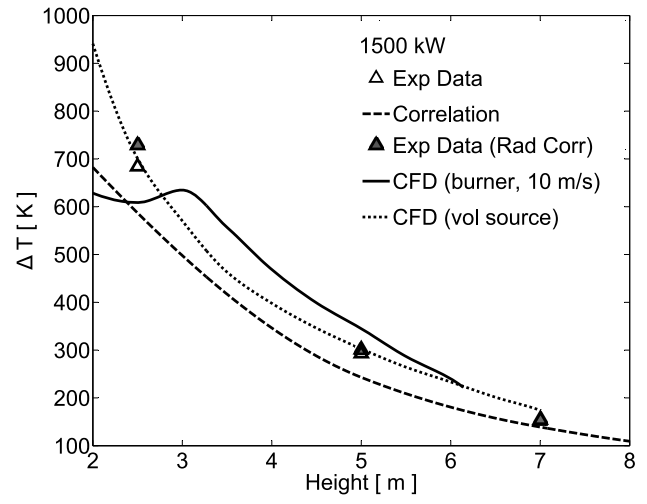

(a)

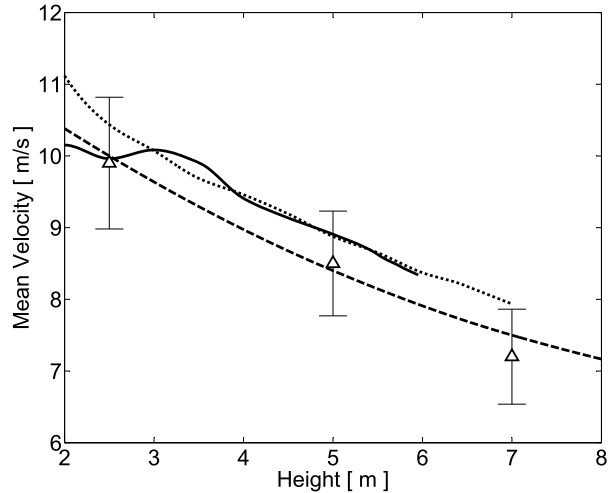

(b)

Fig. 4. Model results for $\dot{Q}_{c}=1500 \mathrm{~kW}$ plume. Time-averaged centerline (a) excess temperature, $\Delta T$, and (b) velocity, $u$, shown as functions of height in absence of the ceiling.

temperature distributions for both $\dot{Q}_{c}$ cases are predicted with good accuracy for higher elevations, and the velocity distributions above $4 \mathrm{~m}$ compare well against the experimental data and correlation.

Based on the air inlet velocity of $10 \mathrm{~m} / \mathrm{s}$ for $\dot{Q}_{c}=1500 \mathrm{~kW}$ and $20 \mathrm{~m} / \mathrm{s}$ for $\dot{Q}_{c}=7500 \mathrm{~kW}$, a linear interpolation was used to determine the inlet air velocities for the $\dot{Q}_{c}$ that were applied for ceiling flow simulations. The air inlet velocity were, therefore, determined to be 12.5 and $15.8 \mathrm{~m} / \mathrm{s}$ for $\dot{Q}_{c}=3000$ and $5000 \mathrm{~kW}$, respectively.

\section{Ceiling Flow Maximum Excess Temperature and Velocity}

Figure 6 shows instantaneous flow structures in the form of contours of $\mathrm{Y}_{\mathrm{CO}_{2}} \approx 0.017$ shaded by density for the $1500 \mathrm{~kW}$ plume impinging on a ceiling at $H=3.0 \mathrm{~m}$. Selection of this particular $\mathrm{Y}_{\mathrm{CO}_{2}}$ value enabled good visualization of the flow structures. Turbulent flow of the ceiling-jet is characterized by the presence of large-scale eddy structures captured by the $(3.0 \mathrm{~cm})^{3}$ fine mesh present below the ceiling. These structures are only resolved accurately in the fine-mesh region that extends $\pm 5 \mathrm{~m}$ from the ceiling centerline. Beyond this region, the flow is not resolved adequately. Simulated data were averaged over $60 \mathrm{~s}$ to extract time-averaged gas excess temperature and velocities under the ceiling. 


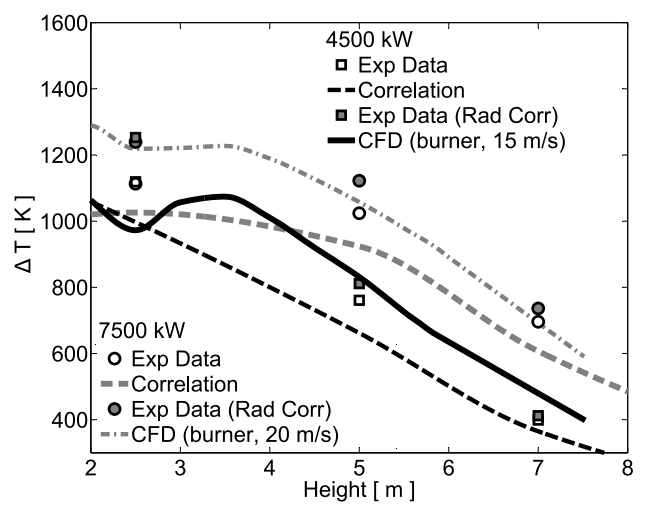

(a)

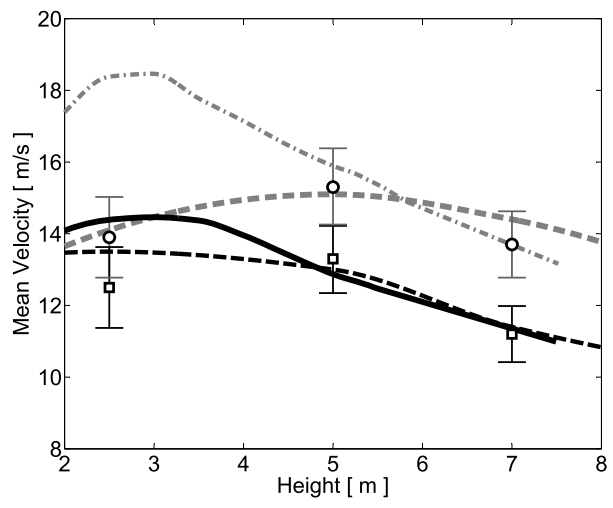

(b)

Fig. 5. Model results for $\dot{Q}_{c}=4500 \mathrm{~kW}$ and $7500 \mathrm{~kW}$ plumes. Time-averaged centerline (a) excess temperature, $\Delta T$, and (b) velocity, $u$, shown as functions of height in absence of the ceiling.

Computed radial distributions of ceiling layer maximum excess temperature, $\Delta T_{\max }$, normalized by the ceiling level centerline excess temperature, $\Delta T_{0}$, and maximum radial velocity, $v_{\max }$, normalized by the ceiling level centerline vertical velocity, $u_{0}$, for three simulation cases are shown in Fig. 7. The x-axis in the figure is $r / b_{\Delta T}$, where $r$ is radial distance in $\mathrm{m}$ and $b_{\Delta T}$ is the plume half-width computed as $b_{\Delta T}=0.108\left(T_{0} / T_{\infty}\right)^{1 / 2}\left(z-z_{0}\right)$, where, $T_{0}=\Delta T_{0}+T_{\infty}$ and the virtual origin, $z_{0}(\mathrm{~m})$ for two-tier storage is $z_{0}=-1.6+0.094 \dot{Q}_{c}^{2 / 5}$ and for threeand four-tier storage is $z_{0}=-2.4+0.095 \dot{Q}_{c}^{2 / 5}$, where, $\dot{Q}_{c}$ is in $\mathrm{kW}$ [23]. Results from cases which have the fires impinging on the ceilings are shown. Comparing with experimental data [17,23], simulated profiles of excess temperature in Fig. 7(a) show a tendency of being on the higher end of the experimental values. This is especially true at the $r / b_{\Delta T}<1$ region where predicted non-dimensional excess temperature values exceed unity since the flame heights for these cases are comparable to the ceiling heights. The maximum value of the excess temperature for these cases also occurs in the $0<r / b_{\Delta T}<1$ region. A distinct peak is visible for the $\dot{Q}_{c}=1500 \mathrm{~kW}, H=3.0 \mathrm{~m}$ simulation, but these peaks are not so obvious for the other cases. This is due to the burner design that uses wide ring burners; individual peaks are the result of multiple fires anchored on the ring and central burners. Individual peaks are due to the presence of multiple flame-sheets impinging on

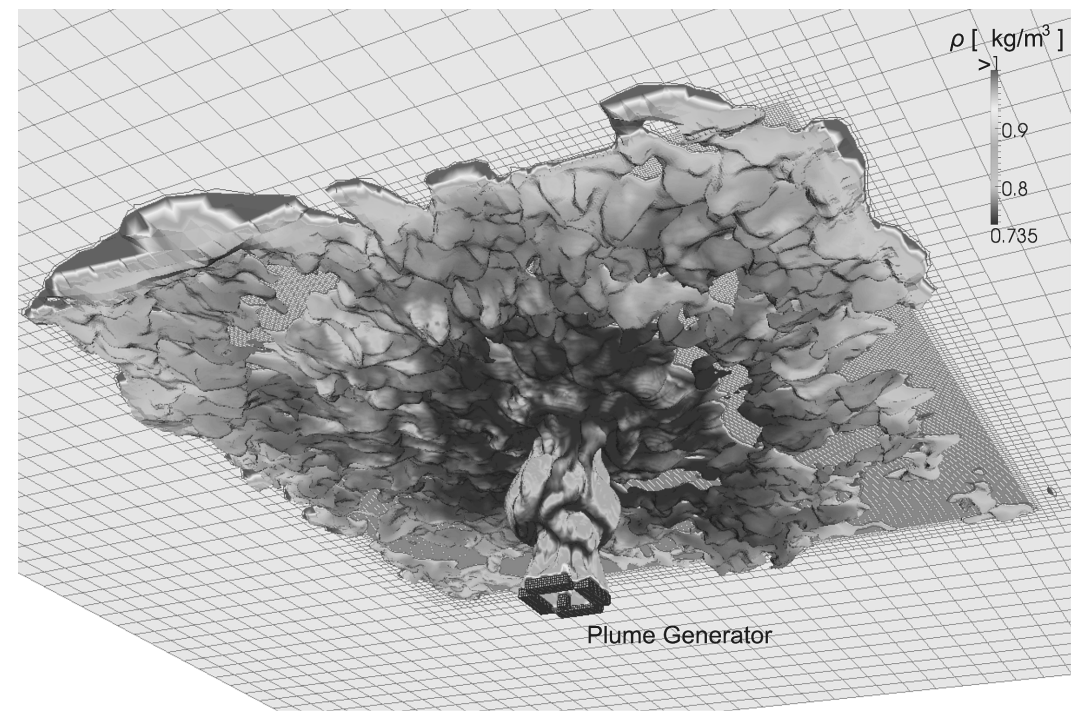

Fig. 6. Instantaneous contour plot of $\mathrm{CO}_{2}$ mass fraction, $\mathrm{Y}_{\mathrm{CO}_{2}} \approx 0.017$, shaded with density values, illustrating flow beneath the ceiling. The plume generator is also shown. 
the ceiling, as in the case of $\dot{Q}_{c}=1500 \mathrm{~kW}$ and $H=3.0 \mathrm{~m}$ (mean flame height, $\ell_{f} \approx 2.94 \mathrm{~m}$ ), $\dot{Q}_{c}=3000 \mathrm{~kW}$ and $H=4.5 \mathrm{~m}\left(\ell_{f} \approx 4.36 \mathrm{~m}\right)$, and $\dot{Q}_{c}=5000 \mathrm{~kW}$ and $H=6.0 \mathrm{~m}\left(\ell_{f} \approx 5.49 \mathrm{~m}\right)$. Such impingement are also observed in the experiments.

Figure 7(b) shows comparisons of the maximum dimensionless radial velocity predictions for impinging fire cases with experimental data from Kung et al [23]. Simulation results consistently show lower values of predicted velocities compared to the experimental data distribution. This is an opposite trend to the one observed for maximum excess temperature, discussed above. This difference between the experimental data and velocity predictions has a small effect on RTI calculations due to its square-root dependence on velocity values, in this case $\sqrt{v_{\max }}$. The predicted non-dimensional maximum velocity distributions show little variation with the case setup for all radial distances, $r / b_{\Delta T}$, similar to the non-dimensional excess temperature which showed similar agreement for $r / b_{\Delta T}>1.5$.

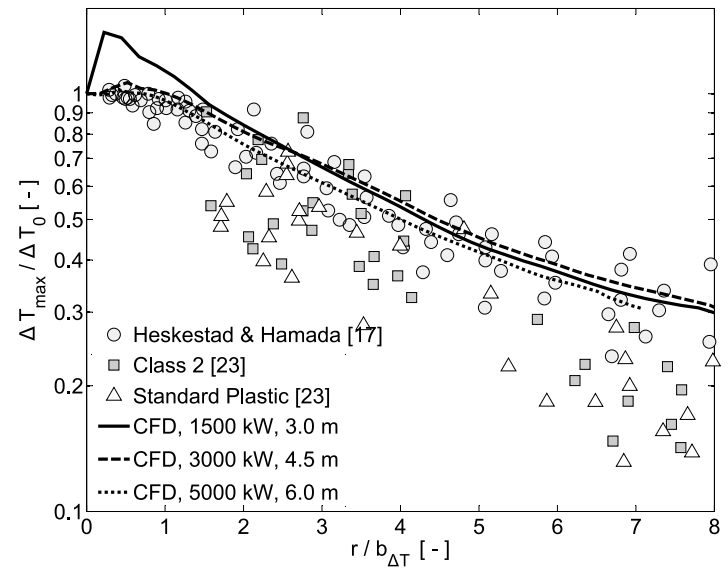

(a)

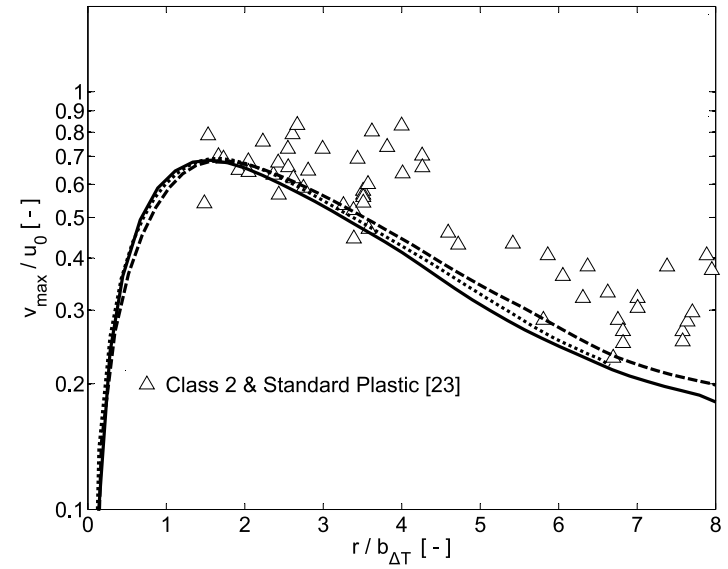

(b)

Fig. 7. Impinging fires: ceiling-jet radial distributions of dimensionless maximum (a) excess temperature, $\Delta T_{\max } / \Delta T_{0}$, and (b) velocity, $v_{\max } / u_{0}$, where $\Delta T_{0}$ and $u_{0}$ are centerline excess temperature and vertical velocity, respectively. Radial distance normalized by plume width, $b_{\Delta T}$.

For cases where the fires are not impinging on the ceilings, non-dimensional maximum excess temperature and velocity are shown in Fig. 8. The major difference between the excess temperature predictions for nonimpinging fire cases compared to impinging fire cases is the absence of the peak at $r / b_{\Delta T}>0$ locations, as can be observed in Fig. 8(a). The peak non-dimensional excess temperature also does not exceed unity, confirming the presence of the peak temperature occurrence on the centerline. The temperature distributions for the three cases also show good agreement with the experimental data; however some divergence of the three predicted curves can be seen for higher $r / b_{\Delta T}$ locations, although these variations are minor. The nondimensional radial velocity predictions shown in Fig. 8(b) are improved compared to the impinging fire cases described earlier. The predicted values are higher and the slopes of the curves are in general agreement with the experimental data. Alpert [29] observed that the peak ceiling gas temperature and velocity occur at vertical distances from the ceiling of less than $1 \%$ of the ceiling clearance, $H$. It can, therefore, be said that irrespective of the fire sizes and ceiling heights, the maximum temperature and velocity can be predicted with acceptable accuracy, particularly for non-impinging fires.

\section{Ceiling Flow Radial Profiles of Excess Temperature and Velocity}

Radial profiles of excess gas temperature, $\Delta T$, and velocity, $v$, for impinging fire scenarios are shown in Fig. 9. Comparisons are made against experimental data collected below the ceiling. The excess temperature is nondimensionalized by $\Delta T_{0}$ and the radial velocity by the centerline vertical velocity, $u_{0}$. The radial distance is non-dimensionalized using the ceiling height, $H$. Plume width, $b_{\Delta T}$, is not used for non-dimensionalization 


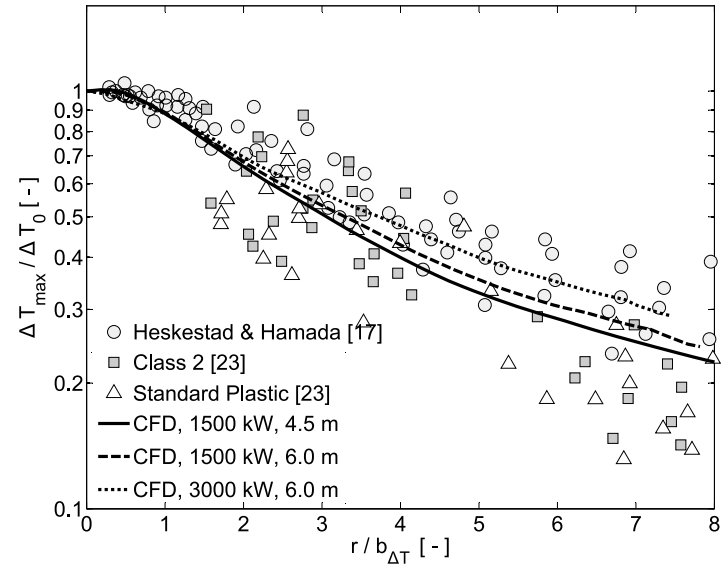

(a)

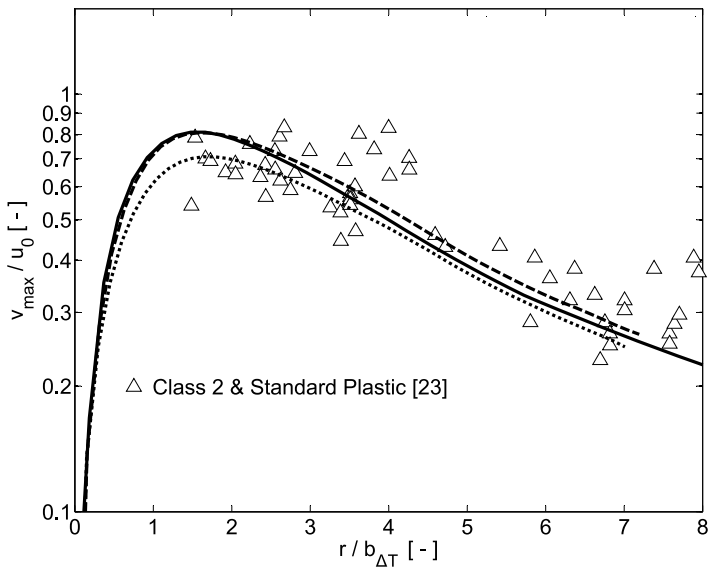

(b)

Fig. 8. Non-impinging fires: ceiling-jet radial distributions of dimensionless maximum (a) excess temperature, $\Delta T_{\max } / \Delta T_{0}$, and (b) velocity, $v_{\max } / u_{0}$, where $\Delta T_{0}$ and $u_{0}$ are centerline excess temperature and vertical velocity, respectively. Radial distance normalized by plume width, $b_{\Delta T}$.
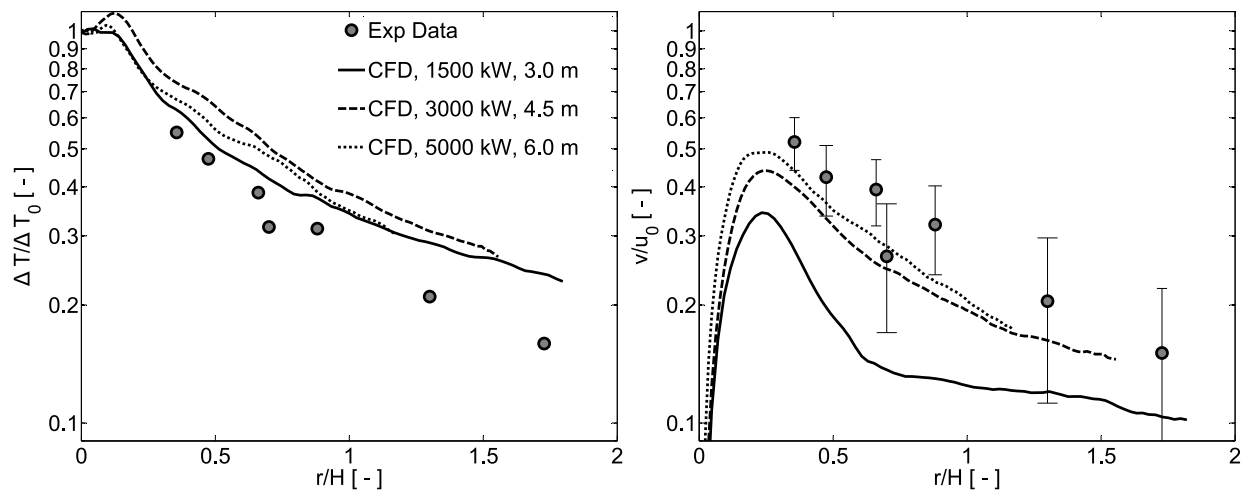

(a) $d_{p}=0.175 \mathrm{~m}$
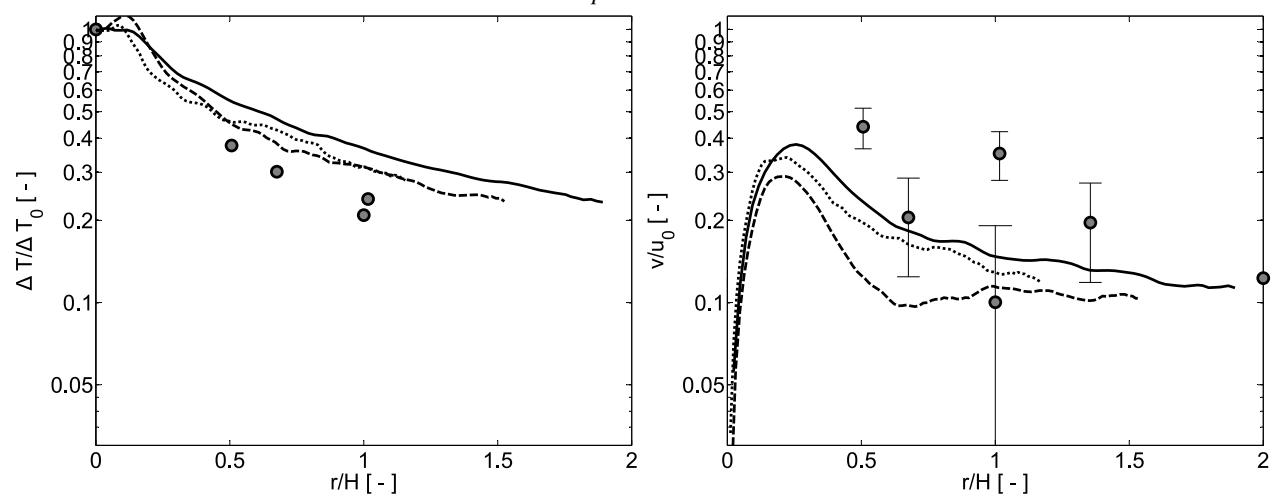

(b) $d_{p}=0.3 \mathrm{~m}$

Fig. 9. Impinging fires: ceiling-jet radial distributions of dimensionless excess temperature, $\Delta T / \Delta T_{0}$, and velocity, $v / u_{0}$ at two depths, $d_{p}=$ (a) $0.175 \mathrm{~m}$, and (b) $0.3 \mathrm{~m}$ below ceiling height, $H$. Velocity error bars correspond to estimated measurement uncertainties. 
as its estimation from the sparse experimental dataset was not possible without the introduction of major assumptions. In Figs. 7 and 8, however, the non-dimensional experimental data plotted were reported as functions of $r / b_{\Delta T}[17,23]$. The comparisons at two depths below the ceiling height, $d_{p}=0.175$ and $0.3 \mathrm{~m}$ are shown in Fig. 9(a) and 9(b), respectively. Non-dimensional excess temperature predictions for all cases show higher values compared to the experimental data at all $r / H$ locations. The presence of the peak temperature at $r / H>0$ also confirms the presence of flames in the vicinity of the ceiling region. At $d_{p}=0.175 \mathrm{~m}$, the temperatures show greater deviation from the experimental data, compared to the distributions at $d_{p}=0.3 \mathrm{~m}$. In general, the slopes of the predicted temperature curves show reasonable agreement with the slope of the experimental data. A steeper decay is observed at $d_{p}=0.175 \mathrm{~m}$, but the agreement is better at $d_{p}=0.3 \mathrm{~m}$ where the slopes indicate a slower decay. The velocity predictions at $d_{p}=0.175 \mathrm{~m}$ show poor agreement in the case of $\dot{Q}_{c}=1500 \mathrm{~kW}$ and $H=3.0 \mathrm{~m}$. The predictions for the higher HRR and ceiling height combinations are improved but overall show under-predicted values compared to experimental data. A similar trend is noticeable at $d_{p}=0.3 \mathrm{~m}$ where velocities are also under-predicted. The $\dot{Q}_{c}=1500 \mathrm{~kW}$ and $H=3.0 \mathrm{~m}$ case produces the highest non-dimensional velocities with predictions worsening with increasing HRR and ceiling height. In summary, the cases where fires are impinging on the ceiling show higher temperatures and lower velocities compared to experimental data.

For non-impinging fire cases, the excess temperature distributions compare favorably with experimental data, as seen in Fig. 10(a). The slopes of the predicted temperature curves at $d_{p}=0.175 \mathrm{~m}$ are aligned with the experimental data, with the $\dot{Q}_{c}=3000 \mathrm{~kW}$ and $H=6.0 \mathrm{~m}$ case showing the greatest deviation. Results using the volumetric fire source case are also included and show very good agreement with experimental data at $d_{p}=0.175 \mathrm{~m}$. The temperature predictions do not collapse at $d_{p}=0.3 \mathrm{~m}$; however the predicted temperatures
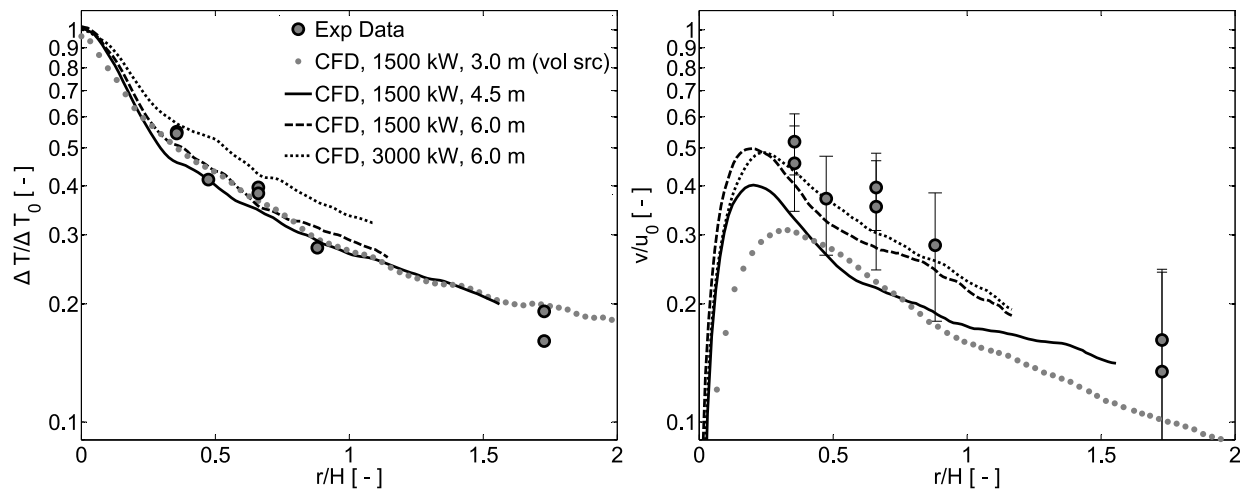

(a) $d_{p}=0.175 \mathrm{~m}$
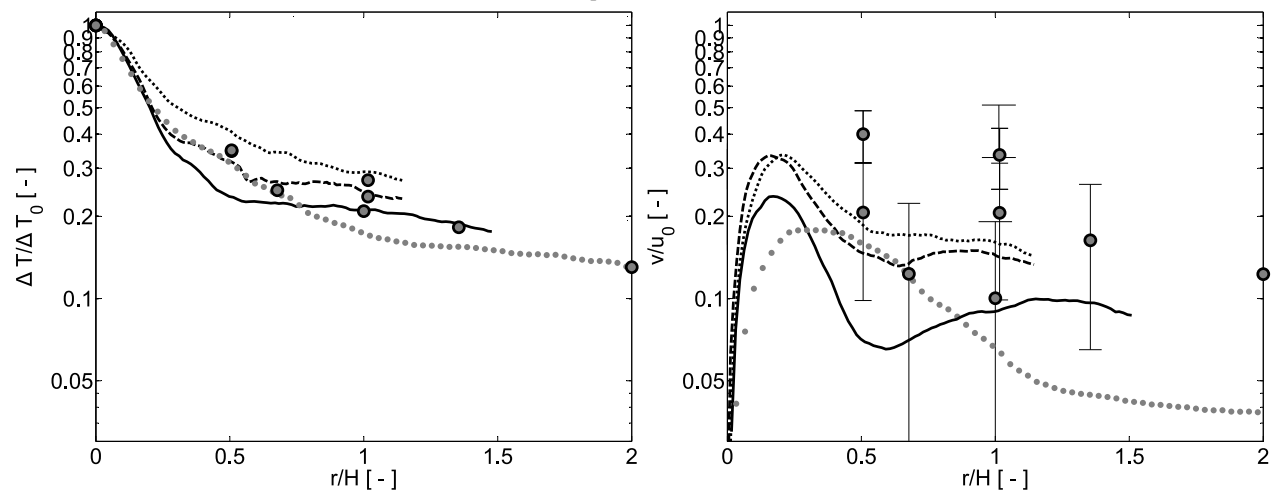

(b) $d_{p}=0.3 \mathrm{~m}$

Fig. 10. Non-impinging fires: ceiling-jet radial distributions of dimensionless excess temperature, $\Delta T / \Delta T_{0}$, and velocity, $v / u_{0}$ at two depths, $d_{p}=$ (a) $0.175 \mathrm{~m}$, and (b) $0.3 \mathrm{~m}$ below ceiling height, $H$. Velocity error bars correspond to estimated measurement uncertainties. 
compare favorably with the experimental data. Figure 10(b) shows velocity predictions using the burner setup at $d_{p}=0.175 \mathrm{~m}$ demonstrating good agreement with experimental data with the $\dot{Q}_{c}=1500 \mathrm{~kW}$ and $H=6.0 \mathrm{~m}$ and $\dot{Q}_{c}=3000 \mathrm{~kW}$ and $H=6.0 \mathrm{~m}$ cases showing similar distributions. The $\dot{Q}_{c}=1500 \mathrm{~kW}$ and $H=4.5 \mathrm{~m}$ case under-predicts the velocities slightly and the volumetric fire source case consistently shows lower predicted velocities, although its predictions are marginally lower. At $d_{p}=0.3 \mathrm{~m}$, the prediction tend to show greater differences between cases. The $\dot{Q}_{c}=1500 \mathrm{~kW}$ and $H=4.5 \mathrm{~m}$ case predicts lower velocities compared to experiments, whereas the two other burner cases show similar behavior and good agreement with data. The volumetric fire source case predicts a smooth variation of velocity with peak values lower than other cases; the predictions shows good agreement with experimental data.

\section{Ceiling Layer Thicknesses}

The depth of the vertical temperature profile below the ceiling, $\delta_{T}$, where $\Delta T / \Delta T_{\max }=1 / e \approx 0.37$ [23], is computed for the six simulation cases and compared against the correlation from Kung et al [23]. The comparison is shown in Fig. 11(a) where the non-dimensional thermal thickness, $\delta_{T} / H$, is plotted against the non-dimensional radial distance, $r / H$. The three gray curves correspond to the cases with flames impinging on the ceiling; the predicted thermal thicknesses are higher than the correlation values by $20-50 \%$. The agreement between the cases with non-impinging fires (black curves) with the correlation are much improved with differences reduced to below $15 \%$. The predicted $\delta_{T}$ values are between $7 \%$ and $12 \%$ of the ceiling clearance for non-impinging fire cases, which compares well with Alpert's estimate of the range between 5.5\% and $12.5 \%$ of the ceiling clearance [29]. The model predictions for the velocity profile depth, $\delta_{v}$, are shown in Fig. 11(b). The predictions for impinging and non-impinging fire cases show the same trend-below $r / H=1$ the predicted $\delta_{v} / H$ values are lower than the correlation with differences of at most $20 \%$ observed; at $r / H>1$ the model predictions are higher with differences becoming larger with increasing $r / H$.

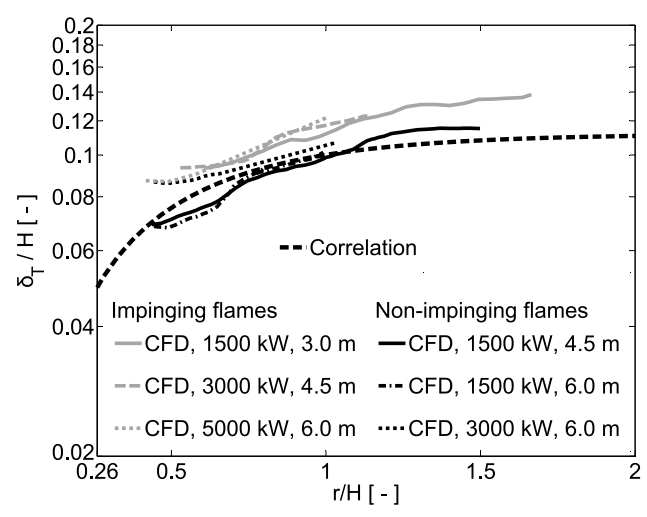

(a)

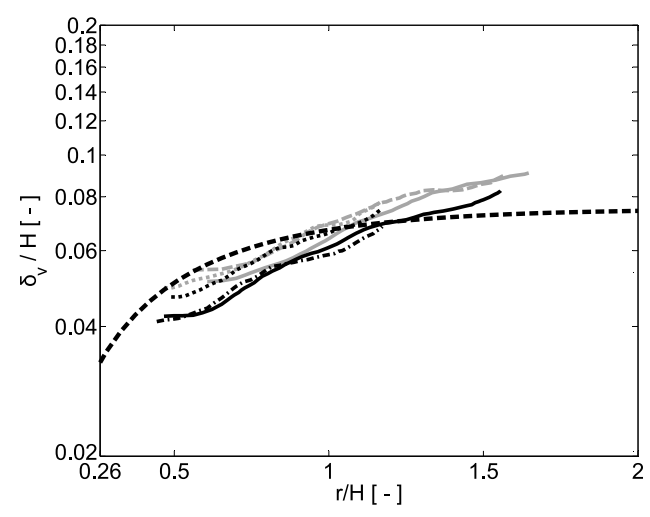

(b)

Fig. 11. Ceiling jet (a) thermal layer thickness, $\delta_{T}$, and (b) velocity boundary layer thickness, $\delta_{v}$. Correlation values of $\delta_{T}$ from Kung et al [23] with the assumption of $\delta_{v}=0.67 \delta_{T}$.

\section{CONCLUSIONS}

Strong plumes of rack-storage fires in the range of $1500-5000 \mathrm{~kW}$ were generated with a designed ADD apparatus burner setup. Ceiling flows developing from these plumes impinging on horizontal ceilings located at 3.0-6.0 m above the ADD apparatus were simulated. Comparisons of predicted excess temperature and velocity were made against experimental data. Cases when flames were impinging on the ceiling, $\ell_{f} / H \sim 1$, produced temperature predictions which were higher than the observed experimental values. Consequently, the thermal layer depth, $\delta_{T}$, for impinging fire ceiling flows were also higher compared to the correlation values. Simulations with flame height shorter than ceiling height, $\ell_{f} / H<1$, produced the best comparison between predicted temperatures and experimental data. An opposite behavior was observed with the impinging fire ceiling flows producing lower velocities. In the case of the velocity layer depth, $\delta_{v}$, no such trend was 
noticeable and all simulations produced comparable thicknesses. It is concluded that in general the applied LES code, FireFOAM, and its models were able to make temperature and velocity predictions in the ceiling layer that were close to experimental data, provided the fires were not impinging on the ceiling.

Future model improvements include more accurate ceiling-level heat transfer modeling (thermal boundary condition) and better estimation of impinging fires driven ceiling flows. For impinging fires, several features of the model, e.g. combustion and turbulence modeling need to be investigated and their impact on prediction of the turning region flow are to be evaluated. RTI calculations with the predicted temperatures and velocities and comparison against correlation based and experimentally observed sprinkler activation times will also be attempted.

\section{ACKNOWLEDGEMENTS}

Thanks are due to Drs. Yibing Xin, Marcos Chaos and Sergey Dorofeev for providing valuable inputs to the study. Dr. Xin made available experimental data from Refs. [17,23], Dr. Chaos contributed plume radiant fraction values and Dr. Dorofeev reviewed the manuscript. The work presented was funded by FM Global and performed within the framework of the FM Global Strategic Research Program on Fire Modeling.

\section{REFERENCES}

[1] Wang, Y., Chatterjee, P., and de Ris, J. L. Large Eddy Simulation of Fire Plumes. Proceedings of the Combustion Institute, 33(2):2473-2480, 2011, http://dx.doi.org/10.1016/j.proci.2010.07.031.

[2] McGrattan, K., Hostikka, S., Floyd, J., and McDermott, R. Fire Dynamics Simulator (Version 5) Technical Reference Guide, Volume 3: Validation. NIST Special Publication 1018-5.

[3] Chatterjee, P., de Ris, J. L., Wang, Y., and Dorofeev, S. B. A Model For Soot Radiation in Buoyant Diffusion Flames. Proceedings of the Combustion Institute, 33(2):2665-2671, 2011, http://dx.doi.org/10.1016/j.proci.2010.06.112.

[4] Chaos, M., Khan, M. M., and Dorofeev, S. B. Pyrolysis of Corrugated Cardboard in Inert and Oxidative Environments. Proceedings of the Combustion Institute, 34(2):2583-2590, 2013, http://dx.doi.org/10.1016/j.proci.2012.06.031.

[5] Meredith, K. V., de Vries, J., Wang, Y., and Xin, Y. A Comprehensive Model for Simulating the Interaction of Water With Solid Surfaces in Fire Suppression Environments. Proceedings of the Combustion Institute, 34(2):2719-2726, 2013, http://dx.doi.org/10.1016/j.proci.2012.06.094.

[6] Meredith, K. V., Chatterjee, P., Wang, Y., and Xin, Y. Simulating Sprinkler Based Rack Storage Fire Suppression under Uniform Water Distribution. In Proceedings of the Seventh Int. Seminar on Fire \& Explosion Hazards, pages 511-520. Providence, RI, May 6-10, 2013.

[7] McGrattan, K. B., Hamins, A., and Stroup, D. Sprinkler, Smoke \& Heat Vent, Draft Curtain Interaction-Large Scale Experiments and Model Development. NIST Report, NISTIR 6196-1, Sep 1998.

[8] Heskestad, G. and Bill, R. G. Quantification of Thermal Responsiveness of Automatic Sprinklers Including Conduction Effects. Fire Safety Journal, 14(1-2):113-125, 1988, http://dx.doi.org/10.1016/0379-7112(88)90049-5.

[9] Custer, R. L. P., Meacham, B. J., and Schifiliti, R. P. Design of Detection Systems. In The SFPE Handbook of Fire Protection Engineering,4e, Section 4: Design Calculations, Chapter 4-1, 2008.

[10] Alpert, R. L. Turbulent Ceiling-Jet Induced by Large-Scale Fires. Combustion Science and Technology, 11(5-6):197-213, 1975, http://dx.doi.org/10.1080/00102207508946699.

[11] You, H.-Z. and Faeth, G. M. An Investigation of Fire Impingement on a Horizontal Ceiling. National Bureau of Standards, Rpt. No. NBS-GCR-79-188, October 1978. 
[12] Motevalli, V. Numerical Prediction of Ceiling Jet Temperature Profiles During Ceiling Heating Using Empirical Velocity Profiles and Turbulent Continuity and Energy Equations. Fire Safety Journal, 22(2):125-144, 1994, http://dx.doi.org/10.1016/0379-7112(94)90069-8.

[13] Cox, G. and Kumar, S. Field Modelling of Fire in Forced Ventilated Enclosures. Combustion Science and Technology, 52:7-23, 1987, http://dx.doi.org/10.1080/00102208708952565.

[14] Tuovinen, H. Validation of Ceiling Jet Flows in Large Corridor with Vents Using the CFD Code JASMINE. Fire Technology, 32:25-49, 1996, http://dx.doi.org/10.1007/BF01040756.

[15] Chow, W. K. Numerical Studies on the Transient Behaviour of a Fire Plume and Ceiling Jet. Mathematical and Computer Modelling, 17(9):71-79, 1993, http://dx.doi.org/10.1016/08957177(93)90017-S.

[16] Hara, T. and Kato, S. Numerical Simulation of Fire Plume-Induced Ceiling Jets Using the Standard

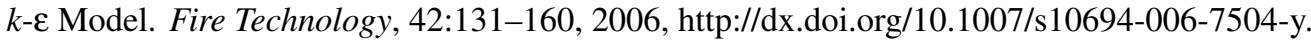

[17] Heskestad, G. and Hamada, T. Ceiling Jets of Strong Fire Plumes. Fire Safety Journal, 21:69-82, 1993, http://dx.doi.org/10.1016/0379-7112(93)90005-B.

[18] O'Grady, N. and Novozhilov, V. Large Eddy Simulation of Sprinkler Interaction With a Fire Ceiling Jet. Combustion Science and Technology, 181:984-1006, 2009, http://dx.doi.org/10.1080/00102200902973158.

[19] Bill, R. G. Numerical Simulation of Actual Delivered Density (ADD) Measurements. Fire Safety Journal, 20(3):227-240, 1993, http://dx.doi.org/10.1016/0379-7112(93)90045-R.

[20] Nam, S. Numerical Simulation of Actual Delivered Density of Sprinkler Spray Through Fire Plumes. Atomization and Sprays, 4(4):385-404, 1994.

[21] McCaffrey, B. J. and Heskestad, G. A Robust Bidirectional Low-Velocity Probe for Flame and Fire Application. Combustion and Flame, 26:125-127, 1976, http://dx.doi.org/10.1016/00102180(76)90062-6.

[22] Nam, S. and Bill, R. G. Numerical Simulation of Thermal Plumes. Fire Safety Journal, 21:231-256, 1993, http://dx.doi.org/10.1016/0379-7112(93)90029-P.

[23] Kung, H.-C., You, H.-Z., and Spaulding, R. D. Ceiling Flows of Growing Rack Storage Fires. Twenty-first Symposium (Int.) on Combustion, pages 121-128, 1986, http://dx.doi.org/10.1016/S0082-0784(88)80238-8.

[24] OpenFOAM: The Open Source CFD Toolbox, User Guide, Version 2.2.0, February 22, 2013.

[25] Kärrholm, F. P., Tao, F., and Nordin, N. Three-Dimensional Simulation of Diesel Spray Ignition and Flame Lift-off Using OpenFOAM and KIVA-3V CFD Codes. SAE Technical Paper 2008-010961, 2008, http://dx.doi.org/10.4271/2008-01-0961.

[26] SALOME6 Brochure: The Open Source Integration Platform for Numerical Simulation, 2011.

[27] Spalding, D. B. A New Analytical Expression for the Drag of a Flat Plate Valid for Both the Turbulent and Laminar Regimes. Int. Journal of Heat and Mass Transfer, 5:1133-1138, 1962, http://dx.doi.org/10.1016/0017-9310(62)90189-8.

[28] You, H.-Z. and Kung, H.-C. Strong Buoyant Plumes of Growing Rack Storage Fires. Twentieth Symposium (Int.) on Combustion, pages 1547-1554, 1984, http://dx.doi.org/10.1016/S00820784(85)80649-4.

[29] Alpert, R. L. Calculation of Response Time of Ceiling-Mounted Fire Detectors. Fire Technology, 8:181-195, 1972, http://dx.doi.org/10.1007/BF02590543. 